to the payment of salaries and wages, the maintenance of stocks, and other expensive activities. Several computers have already been installed by regional hospital boards and it will not be long before they turn up inside hospitals.

Administrative tasks will not load a hospital computer fully, and hence there will rightly be pressure to use the equipment directly for problems of patient care, the medical record providing the interface between the two types of activity. By the time this point is reached decisions will have to be made concerning the form of medical records, their accessibility, and the techniques of recording and reproducing them, and these decisions will impinge directly on the daily work of the medical and nursing staff. It will be well if the decisions are made in full collaboration with doctors who are adequately acquainted with the problems involved, for made they will be, whether such collaboration is forthcoming or not. Rightly used, computers and mathematics have much to offer to the medical profession. Only if the profession is willing to involve itself to the full in their development will the most effective applications be pursued.

\title{
TOMORROW'S BUILDINGS
}

\section{New General Teaching Hospital at Liverpool}

Work is about to start on Phase 2 50-bed units (two on each floor) designed on of the new general teaching hospital at a basically standard pattern. The ward Liverpool. In a booklet describing the design is based on the "race-track" prinhospital, ${ }^{1}$ Mr. A. V. J. Hinds, the Secretary ciple with areas for patients sited on the periof the United Liverpool Hospitals, explains phery of the block and services and corridors that this is intended to replace four relatively forming a central core; most floors contain a small and geographically separated hospitals six-bedded intensive care unit.

(the Royal Infirmary, the Stanley Hospital, David Lewis Northern Hospital, and the Royal Southern Hospital). Work on Phase 1 of the new hospital started in 1965, and includes a training college for nurses, physiotherapists, and other ancillary workers; a residential block; and a boiler house and laundry. Phase 2 of the project includes the main ward block, outpatients department, university clinical departments, and the clinical sciences building. The main block is fourteen storeys high, and contains about 800 beds made up of sixteen

1 The New Medical Teaching Centre for Liverpool. Reprinted from Architecture North West, 1967.
M

Ten operating theatres will be provided linked with sterile nursing unit and intensive therapy unit. The theatres will be connected by television to the viewing galleries above and also to the lecture theatres in the clinical sciences building. The outpatient unit is at ground-floor level and contains 11 clinic suites, each of which will be grouped round landscaped courtyards. This unit will also include a major accident department, two operating theatres for day cases, and departments of physical medicine, radiology, and pharmacy.
The four-storey block containing the university clinical departments will be linked with the wards, each department having direct access to its own ward. In their turn the university clinical departments will be linked to the clinical sciences building. The latter, which will have varying storey heights, will contain the departments of bacteriology and pathology, the medical library, the animal house, and three lecture theatres.

The Medical Teaching Centre will also include a dental hospital and University School of Dental Surgery. These new buildings, the booklet says, will enable the present annual intake of dental students of 35 to be raised to 60 from 1972 onwards and the number of patients treated annually to be raised from 81,500 to 140,000 respectively.

The architects for the new general teaching hospital are William Holford and Associates, Liverpool, and the main contractors for Phase 2 will be Tersons, London.

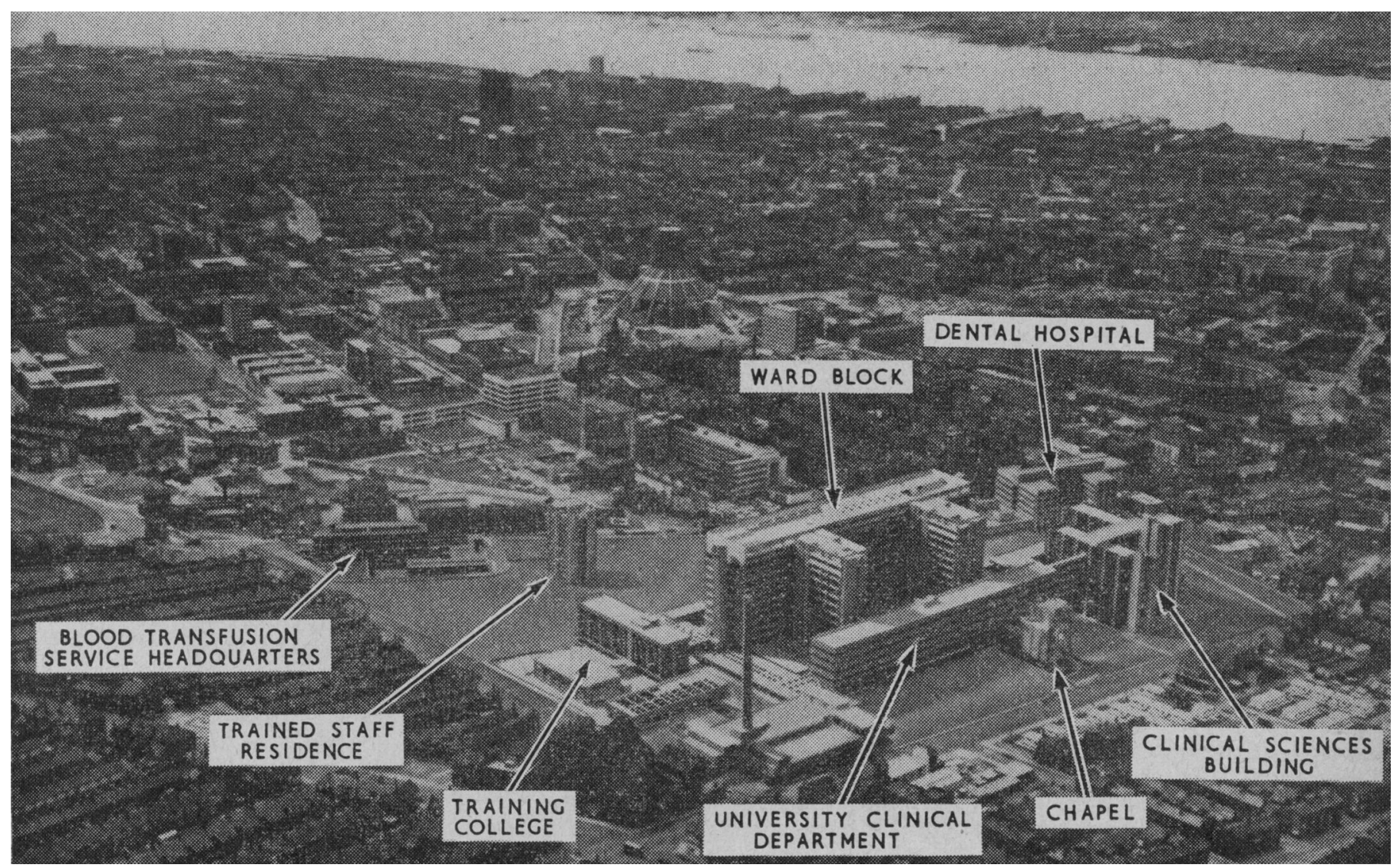

